\title{
The Impact of Risk-Aware Consumer Trust on CB E-Commerce Platforms and Purchase Intention
}

Yi Sun, School of Economics and Management, University of Chinese Academy of Sciences, Beijing, China

Yunrong Li, School of Economics and Management, Dali University, Dali, China

\begin{abstract}
Cross-border e-commerce (CBRC) is increasingly affecting the value of traditional trade due to its rich variety, convenient operation, and freedom from time and space restrictions and has also changed consumer shopping habits. However, the development of CBEC still faces many problems, resulting in domestic consumers' willingness to consume on CBEC platforms not being high. Based on the above background, the research content of this paper is the influence of consumer trust on purchase intention based on perceived risk of CBEC platforms. In this paper, a questionnaire survey is used to collect data for simulation. The results show that from the regression results of the five dimensions of trust on purchase intention, the adjusted R2 is 0.466, indicating a high degree of fit. When the exploratory value in perceived promotional gains is high, it will leave consumers in an irrational state and weaken the perception of risk.
\end{abstract}

\section{KEYWORDS}

Consumer Trust, Cross-Border E-Commerce, Perceived Risk, Purchase Willingness, Supply Chain Relationship

\section{INTRODUCTION}

Trade globalization is not only developing at a rapid pace, but also has a very high degree of depth. Consumers are no longer confined to domestic products when choosing products, and some highquality overseas products have also entered the public's vision (Liu et al., 2019). Earlier, the channels for consumers who were involved in Haitao to obtain overseas products were limited to traditional transfer companies, human backpackers, and purchasing methods, but poor logistics experience, frequent half-month receiving cycles, and high Logistics costs are prohibitive for many people.

With the increasing share of CBEC in e-commerce year by year, e-commerce platforms are springing up (Lu \& Wang, 2016; Wang, 2017). However, due to the relatively new rise of CBEC platforms, the perspective of foreign scholars often falls on the enterprise level (Humair et al., 2016; Wang et al., 2017). However, the development of domestic CBEC is relatively new. Tmall global, Shunfeng optimization, Jumei premium products, tiantianguoyuan and other enterprises officially carry out CBEC business for a short time. Scholars mostly analyze and comb from macro policies, and lack of research on CBEC platforms from the perspective of consumers (Agrawal \& Fox, 2016; Wang et al., 2018). In addition, the development of CBEC platforms has been challenged due to the restrictions in various aspects such as the early stage of industry development and backward Internet management means (Alsaad et al., 2018; Kang et al., 2016). How to make CBEC platform start from 
itself, find better marketing measures and improve the marketing efficiency of the platform needs to be solved (Aljukhadar \& Senecal, 2016; Kim, 2017).

Jia used the geophysical and personal mobile phone data of 157358 victims of the Ya' an earthquake in 2013 to diagnose the impact of the disaster and investigate the actual risk change behavior. Higher seismic intensity does not limit human activities, but leads to the increasing use of communication applications, functional applications (and feature applications). Combining the mobile data with the field survey $(n=2000)$ completed one week after the earthquake, the instrumental variable analysis shows that only the increase of happy behavior can reduce the perceived risk. Therefore, hedonic behavior may become a strategy for coping with and recovering population size, which is often ignored in risk management and policy considerations (Jia et al., 2017; Slovic, 2016). The risk of personal privacy disclosure will prevent consumers from using lbs, but little attention is focused on how to reduce the perceived privacy risk of using lbs. Wang's research focuses on the impact of consumer quality perception on LBS trust, thus affecting perceived privacy risks and the intention of using lbs continuously. Through the market survey website, 1399 valid questionnaires were collected.Structural equation model analysis is applied to the data. Structural equation model analysis is applied to data. (José, 2017; Wang \& Lin, 2016). Using panel data from 2007-2009 consumer finance survey, Schooley studied the changes of people's perceived and realized risk tolerance after the financial crisis (Ji \& Guo, 2015). Households with lower risk tolerance are more likely to reduce their portfolio risk, and vice versa. In addition, households with reduced wealth are more likely to experience lower risk tolerance, and vice versa(Mittendorf, 2017; Schooley \& Worden, 2016).

After reading a lot of relevant literature in this article, it is found that most of the domestic and foreign research on consumers' online shopping willingness is qualitative research. Conclusion There will be some enrichment of related theoretical research in the field of e-commerce, and the study of consumer willingness in consumer behavior also adds some research perspectives.

\section{PROPOSED METHOD}

\subsection{CBEC Platform}

Information flow, capital flow and logistics of traditional international trade are separated, and B2C e-commerce can be completed on one platform, and can be carried out at the same time (Gonçalves et al., 2017; Ji et al., 2016). (Prisha et al., 2017; Y. C, 2016). Compared with traditional trade, CBEC has many advantages, such as many categories of products,simple and diverse payment methods, and faces global consumers, with huge market potential; because of mastering more customer data, enterprises are more able to produce customized products (Gelrandy et al., 2016; Yang et al., 2017). The comparison of the existing main operation modes of CBEC in China is shown in Table 1.

CBEC in the trade pattern removes the spatial and geographical barriers between trading entities, making it possible for borderless consumer products between countries, and CBEC is directly affecting the transformation of the world economy (Kshetri, 2018; Lv et al., 2017; Sheng-Zan, 2016). As for the main body of enterprises, the rise of CBEC has provided enterprises with more diversified business models for more open, multi-dimensional and three-dimensional import and export trade (Hsu, 2016; Xiaofei, 2017). The inflow of overseas goods and the outflow of Chinese products can be circulated on the international market through more channels, which promotes the optimal allocation of resources between different countries and regions, which is beneficial to achieving a win-win situation between enterprises (Cleynenbreugel, 2017; Guo et al., 2020; Huang, 2017). For consumers, it is more convenient to purchase and use high-quality and cheap products from overseas, which provides a wider international perspective (Krämer, 2016; Vakeel et al., 2016). 
Table 1. The main operating models of China's CBEC

\begin{tabular}{|c|c|c|c|c|}
\hline Mode & The way & Advantages & Disadvantages & $\begin{array}{l}\text { Representative } \\
\text { website }\end{array}$ \\
\hline \multirow{2}{*}{$\begin{array}{l}\text { Overseas } \\
\text { purchasing } \\
\text { model }\end{array}$} & $\begin{array}{l}\text { Overseas } \\
\text { purchasing } \\
\text { platform }\end{array}$ & $\begin{array}{l}\text { Rich variety and large } \\
\text { user flow }\end{array}$ & $\begin{array}{l}\text { Doubt the real qualification } \\
\text { of businessmen; establish full } \\
\text { competitive advantage }\end{array}$ & $\begin{array}{l}\text { Taobao Global } \\
\text { Purchase, JD } \\
\text { Overseas Purchase }\end{array}$ \\
\hline & $\begin{array}{l}\text { Friends circle } \\
\text { shopping }\end{array}$ & User stickiness & The model is not sustainable & \\
\hline \multirow{2}{*}{$\begin{array}{l}\text { Proprietary } \\
\text { B2C mode }\end{array}$} & $\begin{array}{l}\text { Comprehensive } \\
\text { self-operated B2C } \\
\text { platform }\end{array}$ & $\begin{array}{l}\text { Strong ability in } \\
\text { CB supply chain } \\
\text { management }\end{array}$ & $\begin{array}{l}\text { Significantly affected by industry } \\
\text { policy changes }\end{array}$ & $\begin{array}{l}\text { The Amazon, No. } 1 \\
\text { sea purchase }\end{array}$ \\
\hline & $\begin{array}{l}\text { Vertical self- } \\
\text { supporting B2C } \\
\text { platform }\end{array}$ & $\begin{array}{l}\text { Decline in supplier } \\
\text { management } \\
\text { capability }\end{array}$ & $\begin{array}{l}\text { Early stage needs larger funding } \\
\text { support }\end{array}$ & $\begin{array}{l}\text { COFCO I buy nets, } \\
\text { honey buds }\end{array}$ \\
\hline \multicolumn{2}{|c|}{$\begin{array}{l}\text { Direct hair / direct shipping } \\
\text { platform mode }\end{array}$} & $\begin{array}{l}\text { Negotiate agreements } \\
\text { directly with reliable } \\
\text { overseas suppliers } \\
\text { with great potential }\end{array}$ & $\begin{array}{l}\text { Slow investment attraction, } \\
\text { insufficient initial capital and } \\
\text { large initial capital demand }\end{array}$ & $\begin{array}{l}\text { Tmall International, } \\
\text { Ocean Terminal, } \\
\text { CB Connect, } \\
\text { Suning Global } \\
\text { Purchase }\end{array}$ \\
\hline \multicolumn{2}{|c|}{$\begin{array}{l}\text { Shopping guide / rebate platform } \\
\text { model }\end{array}$} & $\begin{array}{l}\text { Lighter model and } \\
\text { easier business }\end{array}$ & $\begin{array}{l}\text { In the long run, there is greater } \\
\text { uncertainty in scaling up }\end{array}$ & $\begin{array}{l}55 \text { Haitao, Yitao. } \\
\text { com, Ocean City }\end{array}$ \\
\hline \multicolumn{2}{|c|}{$\begin{array}{l}\text { Overseas merchandise flash sale } \\
\text { model }\end{array}$} & $\begin{array}{l}\text { Form the platform } \\
\text { advantage of } \\
\text { traffic resource } \\
\text { concentration }\end{array}$ & $\begin{array}{l}\text { High requirements on the control } \\
\text { of supply and logistics; high } \\
\text { requirements on the ability of } \\
\text { front-end users to divert and } \\
\text { convert }\end{array}$ & $\begin{array}{l}\text { Mitao.com, Tmall } \\
\text { International, Jumei } \\
\text { Premium }\end{array}$ \\
\hline
\end{tabular}

\subsection{Perceived Risk}

The operation of the system is easy to use in CB online shopping applications in two aspects: the operation interface of CBEC platform is clear and smooth, the functions are simple and easy to use; and the perfect service platform. The imperfect function of the service platform may directly lead to the lack of some functions of the CBEC platform, which is crucial to the system ease of use of CB online shopping (Lv et al., 2018). For example, the current financial service platform cannot provide consumers with installment payment services such as "Huabei installment" through the CBEC platform. Consumers with weak economic capacity can only make loans through other ways first, so as to purchase high-value goods on the CBEC platform, increasing the difficulty of use. At present, CBEC does not have freight insurance service, so it is impossible for consumers to increase purchase guarantee through "one click Check" like domestic e-commerce platform consumption, and the lack of function increases the difficulty of using the operation platform. We should also see that in response to the problem of CBEC customs clearance, Beijing Customs has opened a public information platform, and Hangzhou CBEC comprehensive pilot zone has implemented the "one key customs declaration" business. The optimization and improvement of service platform is also reducing the difficulty of $\mathrm{CB}$ online shopping for consumers.

According to the theory of perceived risk, we know that even the common consumption behavior can not avoid the risk. In every consumption decision-making process, consumers need to evaluate the consumption risk, and determine the final consumption behavior by comparing the possible risks and psychological expectations of consumption behavior. After the emergence of network consumption, not only does it not reduce the consumption risk. On the contrary, due to the information asymmetry between buyers and sellers of Internet transactions, consumers can not fully evaluate the attributes of 
goods before consumption, and the potential risk of online shopping is more than offline shopping risk. The actual risk of online shopping exceeds expectations and will turn to offline shopping. This risk perception will make consumers reduce the transaction frequency for self-protection. The impact mechanism of CB transactions is more complex, which also determines that the risk of CBEC will be higher than that of traditional e-commerce (Zhu et al., 2020). Therefore, even online shopping consumers will be deterred from $\mathrm{CB}$ online shopping.

\subsection{The Influence of Consumer Trust on Purchase Intention of CBEC Platform Based on Perceived Risk}

The multi-dimensional structure of perceived risk is shown in Figure 1.

Figure 1. Multidimensional structure of perceived risk presentation

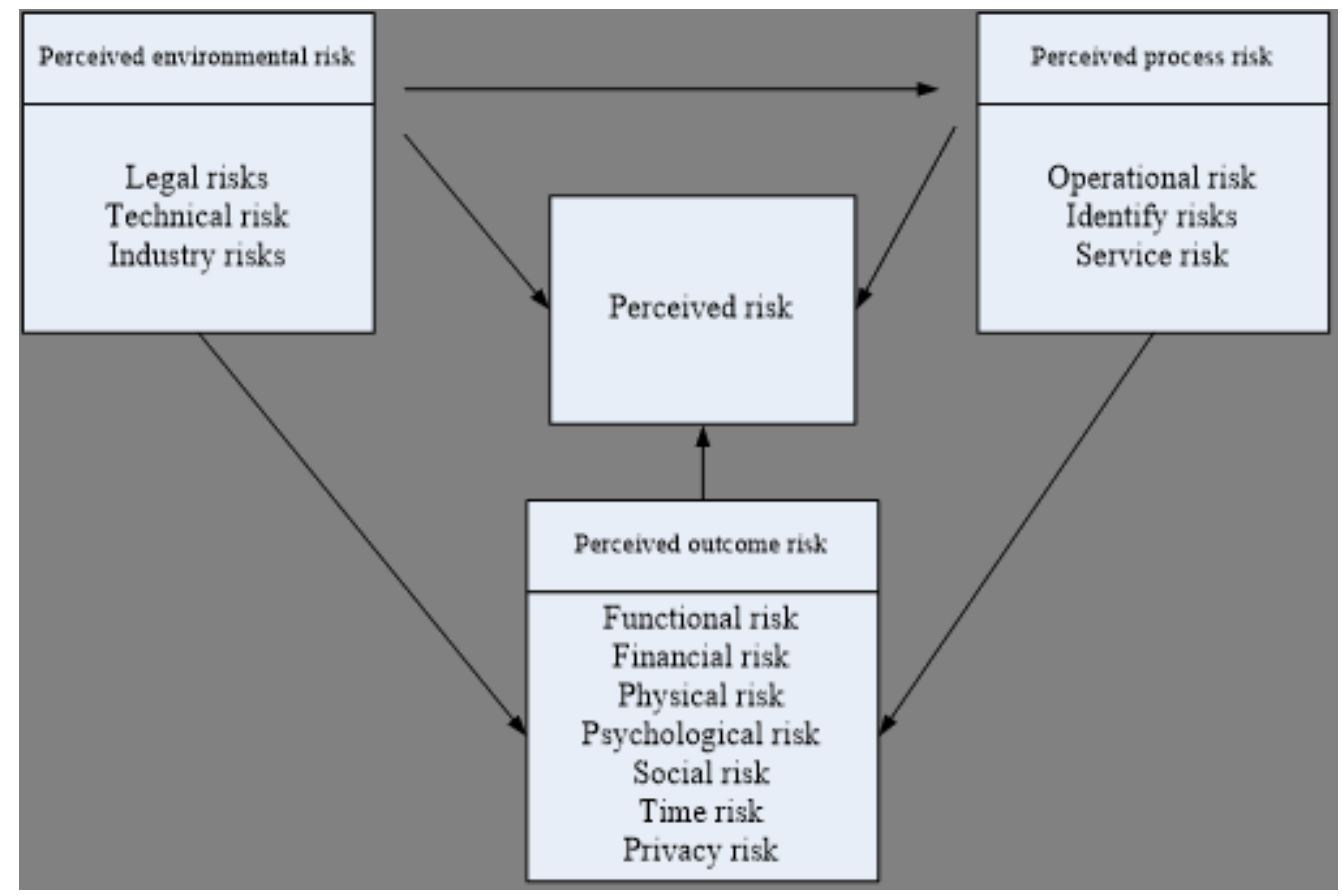

Perceived process risk is consumers' risk cognition of $\mathrm{CB}$ online shopping process; perceived result risk is consumers' risk cognition of $\mathrm{CB}$ online shopping results. From the connotation of category, we can see that perceived environmental risk affects perceived process risk and perceived result risk. At the same time, perceived outcome risk is affected by perceived process risk, which constitutes the whole concept of perceived risk. Consumers' evaluation of risk will change with different transaction stages. That is to say, in different transaction stages, the dimensions and intensity of consumer perceived risk are different. Based on the dynamics of perceived risk and the shortcomings of existing models, two key nodes in the model are intercepted for further study, as shown in Figure 2.

In view of the many factors involved in the formation of perceived risk, the first is the dynamic research of perceived risk in multi-stage decision-making of CB online shopping consumers. Based on the specific multi-stage decision-making situation of CB online shopping, the study of consumers' perception of ordering, payment and logistics Changes in different dimensions of risk and comparison in different contexts (Qu et al., 2015); Second, the coupling research on perceived risk of CB online 


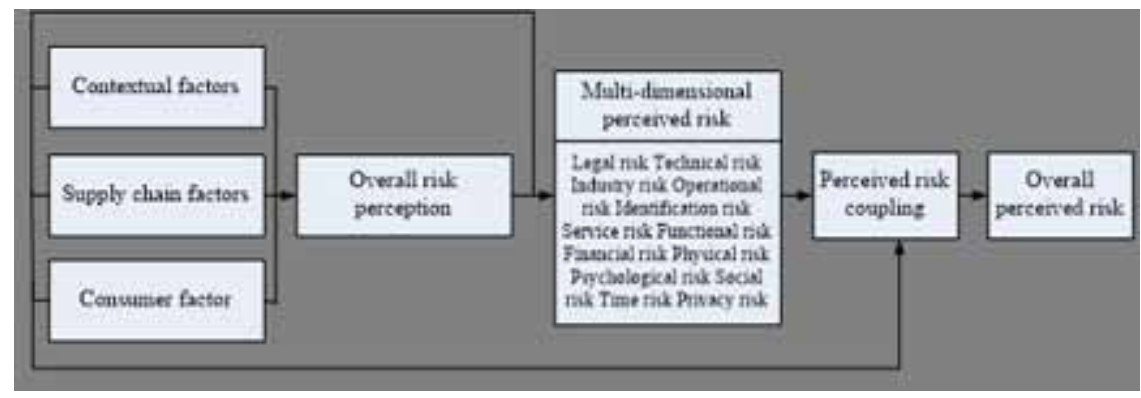

shopping consumers' multi-stage decision-making: Aiming at the innovative subject of "perceived risk coupling", the existing research framework of risk coupling is used for reference. The system analyzes the coupling mechanism of perceived risk, and conducts useful exploration in the interaction of the factors that influence the coupling of perceived risk.

Compared with traditional offline shopping and domestic online shopping, CB online shopping is undoubtedly a "risk event" due to the expansion of shopping scope and unfamiliar shopping situation. The powerful deterrence of Murphy's law makes many consumers cautious in CB online shopping. Even in the face of small probability events such as payment password leakage, bank card swiping, lost goods, etc., they will think that there is a great possibility of occurrence, that is, after the objective risk of the small overview is processed by human brain information, it may produce the amplified perceived risk; in addition, in addition to the amplification of risk intensity, Under the effect of Murphy's law, some consumers will associate the causes and structural relationships of risks. For example, the packaging damage in the transportation of goods may affect the quality of goods and thus endanger the safety of use, that is, from perceiving financial risks to perceiving physical risks. Therefore, Murphy's law has a strong psychological effect, which affects consumers' subjective cognition of risk intensity and risk structure, and makes consumers' perception of risk coupled.

In CB online shopping, "order payment logistics" is not only the basic transaction process, but also the three decision-making stages that consumers must make. First of all, there is a certain time series between the three stages of decision-making, that is, consumers' order decision, payment decision and logistics decision are not made at the same time, but in the order of business relations, which provides the possibility for the formation and role of psychological set. Secondly, there are certain similarities and differences in the three decision-making stages, that is, although there are objective differences in the risk situation of the three links of ordering, payment and logistics, many CB shopping websites often provide "one-stop" and "one-stop" services to optimize the shopping experience of consumers. Under the influence of psychological stereotype, due to the change of risk status in different decision-making stages, some consumers will be based on the same website and similarity, and other consumers will perceive the risk in the later stage, so that the perceived risk in the later stage is restricted by the perceived risk in the earlier stage, resulting in cognitive bias. However, no matter which direction, psychological stereotype will lead to the mutual influence of perceived risk in the first and second stages.

\section{EXPERIMENTS}

\subsection{Experimental Setup and Environment}

The purpose of this paper is to study the influence of consumer trust on purchase intention and the intermediary effect of perceived risk between them. From the theoretical review, this paper confirms that perceived information quality, perceived privacy protection, perceived security protection, third- 
party authentication, website reputation are different observation dimensions of consumer trust. Firstly, this paper reviews the related industry reports of CBEC websites, and selects more mature market areas for the people with higher consumption frequency. Then through the literature reading, select the test indicators of variables. Through pre investigation, eliminate the low quality indicators, and complete the purification of the scale. And further exploratory factor analysis to see whether the theoretical framework is reasonable. Then, a formal questionnaire was conducted. The overall statistics and descriptive statistics of the scale are carried out, the reliability and validity of the data are tested, and the research hypothesis is constructed and verified.

\subsection{Subjects and Data Sources}

Taking the $\mathrm{CB}$ B2C e-commerce market as the research point and the $\mathrm{CBEC}$ website as the media, only including the $\mathrm{CB}$ import and retail in CBEC transactions, excluding the CBEC B2B part. The main consumers of $\mathrm{CB}$ online shopping are people who like $\mathrm{CB}$ online shopping mostly work in wholly-owned, joint-venture or foreign-funded enterprises, and generally have a higher education level (Chin et al., 2016). Most families have a monthly income of more than 11000 yuan. At present, the CB shopping population is mainly high educated and high-income people. The consumers with bachelor's degree or above accounted for $72 \%$ of the total overseas Taoists, and the consumers with monthly household income of more than 10000 yuan accounted for $82 \%$. But the main force of overseas Taoists is still 28-35 years old. This paper chooses a mature CBEC platform consumer market field - Shanghai, aged 20-40 years old, with higher education background as the research object. The investigation started on May 1, 2019 and ended on May 25, 2019. The respondents are mainly consumers aged 23-40 (Bachelor degree or above) in Shanghai. The distribution and recycling methods of the questionnaire include: entrusting friends and classmates to distribute and recycle, and electronic distribution and recycling methods of questionnaire stars. The selection criteria of the questionnaire are: 45 items without CBEC platform shopping experience and all options are the same in the formal questionnaire are excluded. A total of 386 questionnaires were sent out, 375 of which were recovered, with a recovery rate of $96.6 \% ; 267$ of which were valid, with a recovery rate of $72.3 \%$.

\section{DISCUSSION}

\subsection{Regression Analysis}

In this paper, the sample data is standardized, and the research hypothesis that perceived usefulness,

Table 2. Regression Analysis

\begin{tabular}{|c|c|c|c|c|c|c|}
\hline \multirow{2}{*}{$\begin{array}{l}\text { Dependent } \\
\text { variable }\end{array}$} & \multirow{2}{*}{$\begin{array}{l}\text { Independent } \\
\text { variable }\end{array}$} & \multicolumn{2}{|c|}{ Nonstandardized coefficient } & \multirow{2}{*}{$\frac{\text { Standardization }}{\text { Beta }}$} & \multirow{2}{*}{$\mathbf{t}$} & \multirow{2}{*}{ Sig } \\
\hline & & B & Standard error & & & \\
\hline \multirow{4}{*}{$\begin{array}{l}\text { Online shopping } \\
\text { willingness }\end{array}$} & Constant & 3.482 & 0.262 & & 13.318 & 0.000 \\
\hline & Perceptually useful & 0.334 & 0.068 & 0.382 & 4.852 & 0.000 \\
\hline & Easy to use & 0.145 & 0.069 & 0.166 & 2.114 & 0.037 \\
\hline & Perceived risk & -0.357 & 0.069 & -0.333 & -5.241 & 0.000 \\
\hline
\end{tabular}

perceived ease of use and perceived risk affect purchase intention is verified by regression analysis. The processing results are shown in Table 2 .

The regression analysis is shown in Figure 3. 


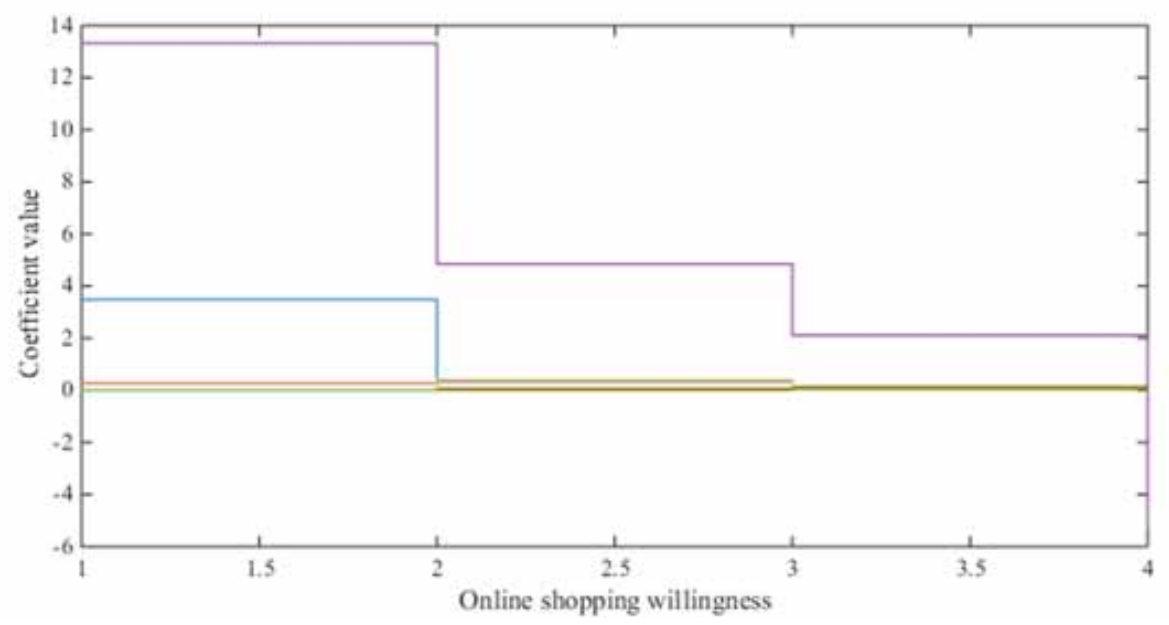

Combining Table 2 and Figure 3 shows that the coefficients of the regression models in this study are all above 0.1 , and the sig.According to the regression results, we believe that perceived usefulness and perceived ease of use have a positive effect on CB online shopping willingness, and that the perceived usefulness is more significant than the positive effect of perceived ease of use $(0.334>0.115)$. It means that for consumers, perceived usefulness is more stimulating to their consumption than perceived ease of use. By increasing product categories, reducing consumer prices, and increasing consumption efficiency, it is easier for consumers to generate consumer willingness. Perceived risk has a significant negative effect on the willingness to buy online, and the influence factor on the willingness to buy online across borders is 0.359 , indicating that the risk factor is also the most sensitive factor for consumers. The current weak consumer demand for imported CBEC is inseparable from consumers' concerns about economic, psychological, social, and privacy risks. Through empirical analysis, the correctness of hypotheses $\mathrm{H} 1, \mathrm{H} 2$, and $\mathrm{H} 3$ was verified again.

\subsection{Test of H2 Hypothesis}

The research examines the coupling effect of supply chain relationships and product characteristics on perceived risk. The repeated measurement variance method using a $2 \times 2$ two-factor mixed experiment design is shown in Figure 4.

It can be seen from the figure that the coupling direction of perceived risk can be tested by the positive and negative differences before and after the coupling of perceived risk. The average value of perceived risk difference (TZ1) of functional products in close supply chain relationship is - 1.111 $<0$, indicating that the coupling direction is negative; in loose supply chain relationship, the average value of perceived risk difference is $1.357>0$, indicating that the coupling direction is positive, so the hypothesis of $\mathrm{H} 2 \mathrm{~A}$ and $\mathrm{H} 2 \mathrm{~B}$ is supported. Under the close supply chain relationship, the average value of perceived risk difference of characteristic products is $-0.222<0$, indicating that the coupling direction is negative; under the loose supply chain relationship (GX2), the average value of perceived risk difference is $-0.101<0$, indicating that the coupling direction is negative, so $\mathrm{H} 2 \mathrm{C}$ hypothesis is not tenable, while $\mathrm{H} 2 \mathrm{D}$ hypothesis is tenable.

\subsection{Analysis of the Influence of Consumer Trust on Purchase Intention}

Taking trust as independent variable and purchase intention as dependent variable, the regression analysis of consumer trust on purchase intention is shown in Figure 5. 
Figure 4. Comparison on perceived risks coupling effect

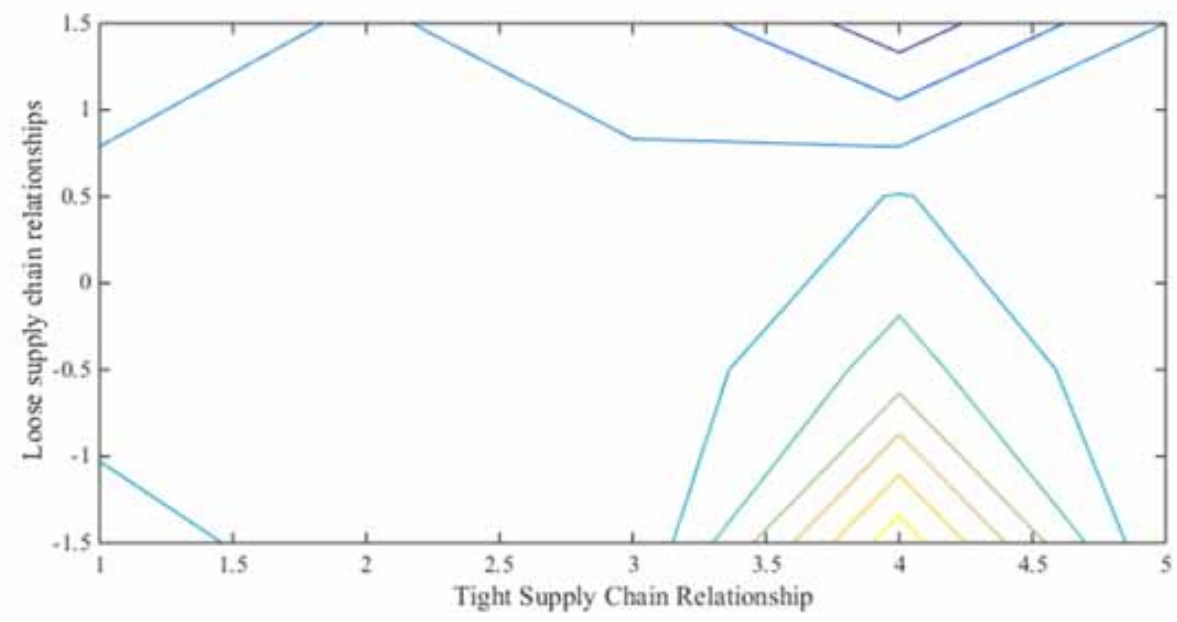

Figure 5. Regression analysis of consumer trust and purchase intention

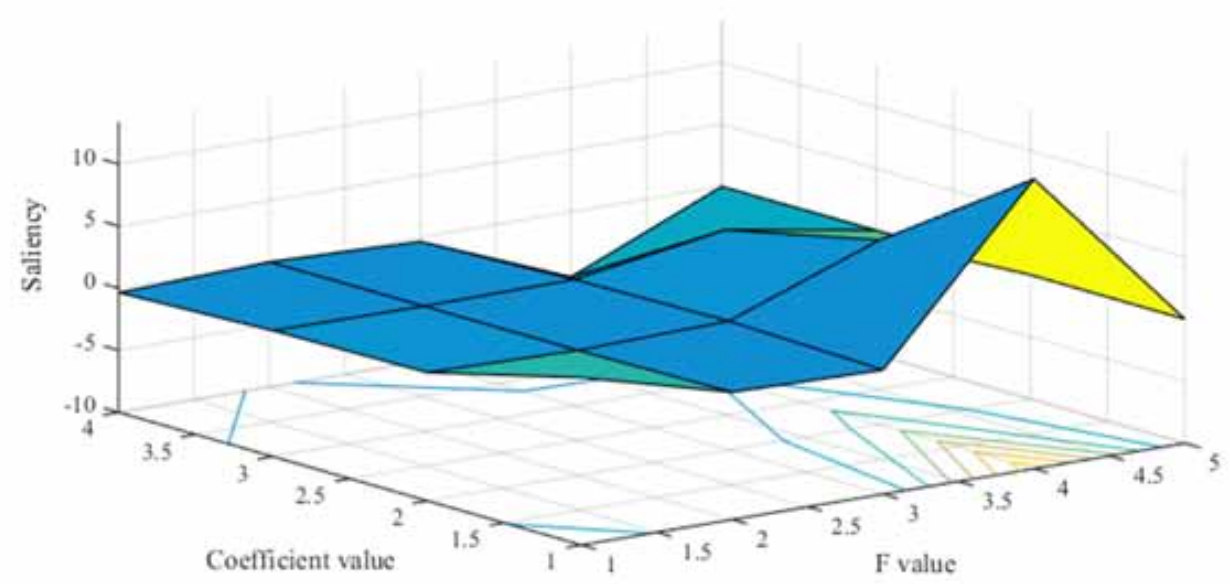

The regression analysis is based on five dimensions: trust, third-party authentication, website reputation, perceived security protection, perceived privacy protection and perceived information quality. Results as shown in the above table, except for the third-party certification, the other four dimensions passed the significance test (significance level is 0.01 ). Therefore, there is a significant linear relationship between website reputation, perceived security protection, perceived privacy protection, perceived information quality and response variables. The change of independent variable can better explain the change of purchase intention. According to the regression results of trust degree to purchase intention, the adjusted $\mathrm{R} 2$ is 0.466 , with a high degree of fit. From the regression effect, $F$ value reached 47.963, reaching a significant level, with a significant level of 0.00 . From the regression coefficient, website reputation, perceived security protection, perceived privacy protection 
and perceived information quality have a significant positive impact on purchase intention, while third-party authentication has no significant impact on purchase intention.

\subsection{The Moderating Effect of Perceived Promotion Revenue}

In order to verify whether the perceived promotional profit significantly affects the willingness to $\mathrm{CB}$ online shopping, and to verify the effect of the perceived promotional profit on perceived usefulness, the adjustment analysis of the perceived promotional profit is shown in Figure 6.

The results of multiple linear regression show that perceived promotion gains have a significant positive impact on $\mathrm{CB}$ online shopping willingness, which verifies the correctness of the research hypothesis H6. In the process of promotion, consumers can benefit from it, and it is easier to build a good impression of CBEC platform. Under the stimulation of price promotion and external pressure, it produces impulsive consumption psychology. Therefore, we believe that the operators of CBEC platforms are good at using promotional activities to increase consumers' perceived promotional profits and achieve the purpose of increasing new users. According to the regulatory effect analysis, we found that perceived promotion benefits play a positive regulatory role in perceived usefulness, perceived ease of use and CB online shopping willingness, and a negative regulatory role in perceived risk and online shopping willingness. When the exploratory value of perceived promotion gains is high, it will make consumers in an irrational state and weaken the perception of risk.

Figure 6. Adjustment Analysis of Perceived Promotional Profits

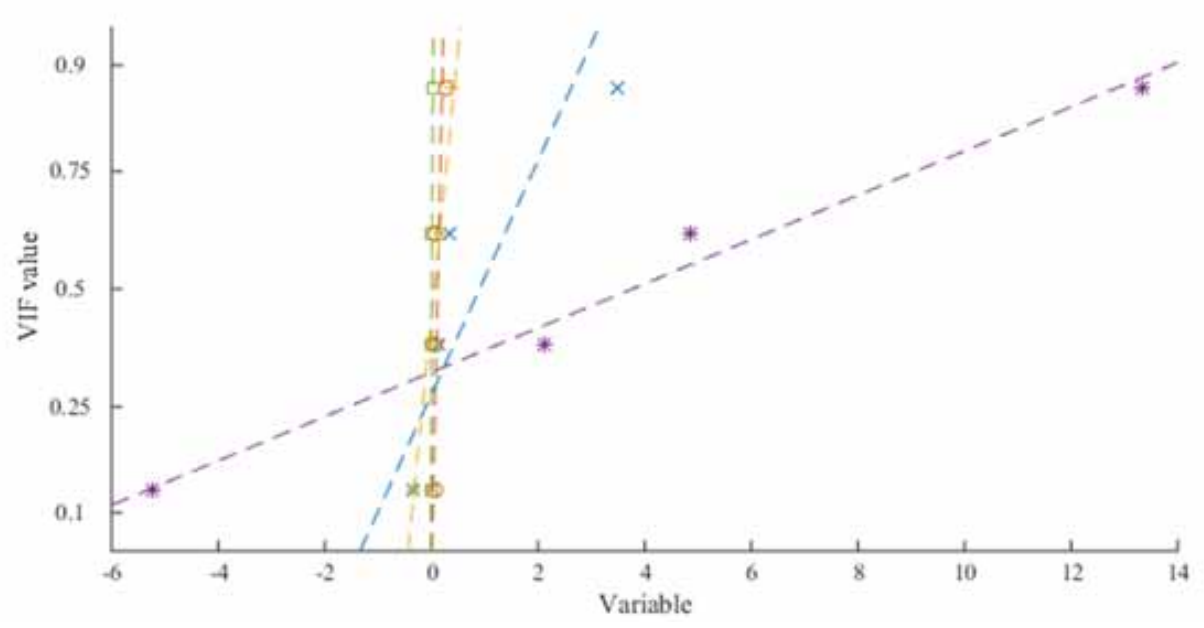

\section{CONCLUSION}

This paper constructs a CBEC purchase intention model. This paper explores the current development of CBEC from the perspective of consumers, and points out the specific problems including weak promotion ability, poor usefulness, poor usability and high risk. Due to the short development of CBEC platform, most of the relevant literature is theoretical data. Based on the empirical model, this paper explains the reasons for the low level of development of import CBEC, and appropriately supplements the theoretical and empirical research of CBEC.

There are still some shortcomings in this paper. This paper does not consider the demographic characteristics of consumers, and it has some limitations to explain the specific consumption intention of consumers with different characteristics. Because in the actual process, the personal characteristics 
of consumers will also have an impact on the willingness to consume, but there is no more detailed and in-depth distinction for consumers in this paper. And the three regulatory variables selected in this paper, such as perceived promotion gains, perceived popularity and cultural values, are only factors that can explain the real problems according to the analysis, and cannot cover all factors that affect the change of consumption intention. 


\section{REFERENCES}

Agrawal, D. R., \& Fox, W. F. (2016). Taxes in an E-Commerce Generation. CESifo Working Paper Series, 24(5), 903-926.

Aljukhadar, M., \& Senecal, S. (2016). The user multifaceted expertise: Divergent effects of the website versus e-commerce expertise. International Journal of Information Management, 36(3), 322-332. doi:10.1016/j. ijinfomgt.2015.11.006

Alsaad, A., Mohamad, R., Taamneh, A., \& Ismail, N. A. (2018). What drives global B2B e-commerce usage: An analysis of the effect of the complexity of trading system and competition pressure. Technology Analysis and Strategic Management, 30(214), 1-13. doi:10.1080/09537325.2018.1432853

Chin, T., Tsai, S. B., Fang, K., Zhu, W., Yang, D., Liu, R. H., \& Tsuei, R. T. C. (2016). EO-Performance Relationships in Reverse Internationalization by Chinese Global Startup Oems: Social Networks and Strategic Flexibility. PLoS One, 11(9), e0162175. doi:10.1371/journal.pone.0162175 PMID:27631368

Cleynenbreugel, P. V. (2017). The European Commission's Geo-blocking Proposals and the Future of EU E-commerce Regulation. Masaryk University Journal of Law and Technology, 11(1), 39-62. doi:10.5817/ MUJLT2017-1-3

Gelrandy, D., Nurhayati, O. D., \& Widianto, E. D. (2016). Pembuatan Aplikasi Warung Keluarga Sebagai Aplikasi E-Commerce Berbasis Web dan Mobile. Jurnal Teknologi Dan Sistem Komputer, 4(2), 432-441. doi:10.14710/ jtsiskom.4.2.2016.432-441

Gonçalves, R., Rocha, T., \& Martins, J. (2017). Evaluation of e-commerce websites accessibility and usability: An e-commerce platform analysis with the inclusion of blind users. Universal Access in the Information Society, (18), 1-17.

Guo, J., Zhang, X., Gu, F., Zhang, H., \& Fan, Y. (2020). Resource-Constrained Innovation Method for Sustainability: Application of Morphological Analysis and TRIZ Inventive Principles. Journal of Cleaner Production, 249, 119372. doi:10.1016/j.jclepro.2019.119372

Hsu, L. F. (2016). E-Commerce Model Based on the Internet of Things. Advanced Science Letters, 22(10), 3089-3091. doi:10.1166/asl.2016.7992

Huang, J. (2017). Comparison of E-commerce Regulations in Chinese and American FTAs: Converging Approaches, Diverging Contents, and Polycentric Directions? Netherlands International Law Review, 64(8), 309-337. doi:10.1007/s40802-017-0094-1

Humair, F., Humair, L., Kuhn, F., \& Kueffer, C. (2016). E-commerce trade in invasive plants. Conservation Biology, 29(6), 1658-1665. doi:10.1111/cobi.12579 PMID:26249172

Ji, Q., \& Guo, J. F. (2015). Oil Price Volatility and Oil-Related Events: An Internet Concern Study Perspective. Applied Energy, 137(1), 256-264.

Ji, Y., Xu, X., \& Sun, Y. (2016). Cooperation strategies for e-commerce platforms with seller classification. Kybernetes, 45(9), 1369-1386. doi:10.1108/K-12-2015-0318

Jia, S., Jia, J., Hsee, C., \& Shiv, B. (2017). The Role of Hedonic Behavior in Reducing Perceived Risk: Evidence From Postearthquake Mobile-App Data. Psychological Science, 28(1), 23-35. doi:10.1177/0956797616671712 PMID:27881710

José, D. (2017). Villalobos, Sirin C V. The Relevance of Emotions in Presidential Public Appeals: Anger's Conditional Effect on Perceived Risk and Support for Military Interventions. Presidential Studies Quarterly, 47(1), 146-168. doi:10.1111/psq.12349

Kang, D., Jang, W., \& Park, Y. (2016). Evaluation of e-commerce websites using fuzzy hierarchical TOPSIS based on E-S-QUAL. Applied Soft Computing, 42(C), 53-65. doi:10.1016/j.asoc.2016.01.017

Kim, M. J. (2017). How to Promote E-Commerce Exports to China: An Empirical Analysis. Social Science Electronic Publishing, 39(2), 53-74.

Krämer, A. (2016). Experiences and Future Expectations towards Online Courses -An Empirical Study of the B2C-and B2B-Segments. Journal of Education and Training Studies, 4(1), 23-31. 
Kshetri, N. (2018). Rural e-Commerce in Developing Countries. IT Professional, 20(2), 91-95. doi:10.1109/ MITP.2018.021921657

Liu, Z., Feng, J., \& Liu, B. (2019). Pricing and service level decisions under a sharing product and consumers' variety-seeking behavior. Sustainability, 11(24).

Lu, B., \& Wang, H. (2016). Research on the Competitive Strategy of CB E-Commerce Comprehensive Pilot Area Based on the Spatial Competition. Scientific Programming, 2016(1), 1-9.

Lv, Z., Li, X., \& Li, W. (2017). Virtual reality geographical interactive scene semantics research for immersive geography learning. Neurocomputing, 254, 71-78. doi:10.1016/j.neucom.2016.07.078

3Lv, Z., Li, X., Wang, W., Zhang, B., Hu, J., \& Feng, S. (2018). Government Affairs Service Platform for Smart City. Future Generation Computer Systems, 81, 443-451. doi:10.1016/j.future.2017.08.047

Mittendorf, C. (2017). Create an Uber account? An investigation of trust and perceived risk in the sharing economy. Journal of Customer Behaviour, 16(3), 281-307. doi:10.1362/147539217X15071081721134

Prisha, P., Neo, H. F., \& Ong, T. S. (2017). E-Commerce Security and Identity Integrity: The Future of Virtual Shopping. Journal of Computational and Theoretical Nanoscience, 23(8), 7849-7852.

Qu, Q., Chen, K. Y., Wei, Y. M., Liu, Y., Tsai, S. B., \& Dong, W. (2015). Using Hybrid Model to Evaluate Performance of Innovation and Technology Professionals in Marine Logistics Industry. Mathematical Problems in Engineering, 2015, 2015. doi:10.1155/2015/361275

Schooley, D., \& Worden, D. D. (2016). Perceived and Realized Risk Tolerance: Changes During the 2008 Financial Crisis. Financial Counseling and Planning, 27(2), 265-276. doi:10.1891/1052-3073.27.2.265

Sheng-Zan, Z. (2016). Study on the focus strategy of e-commerce enterprise under the background of "Internet+": A case study of Kunming Ch999. Ecological Economics, (2), 191-200.

Slovic, P. (2016). Understanding Perceived Risk: 1978-2015. Environment, 58(1), 25-29. doi:10.1080/00139 157.2016.1112169

Vakeel, K. A., Das, S., \& Udo, G. J. (2016). Do security and privacy policies in B2B and B2C e-commerce differ? A comparative study using content analysis. Behaviour \& Information Technology, 36(4), 1-14.

Wang, D., Zha, Y., Bi, G., \& Chen, Y. (2018). A Meta-analysis of Satisfaction-Loyalty Relationship in E-Commerce: Sample and Measurement Characteristics as Moderators. Wireless Personal Communications, 103(1), 941-962. doi:10.1007/s11277-018-5488-9

Wang, S. T., \& Lin, R. L. (2016). Perceived quality factors of location-based apps on trust, perceived privacy risk, and continuous usage intention. Behaviour \& Information Technology, 36(2), 1-9. doi:10.1080/014492 9X.2016.1143033

Wang, Y., Zhang, S., \& Fu, J. (2017). A study on the optimization design of the training program of curriculum system for CB e-commerce talents in higher vocational colleges based on the CIPP model. Revista de la Facultad de Ingeniería, 32(8), 589-596.

Wang, Y. K. (2017). Model for Evaluating the Logistics Service Quality of CB E-Commerce Enterprises with Intuitionistic Fuzzy Information. Journal of Computational and Theoretical Nanoscience, 14(2), 1136-1139. doi:10.1166/jetn.2017.6417

Xiaofei, D. (2017). E-commerce:Sales Expressway for Farm Produce. China Today, (3), 52-54.

Y. C. (2016). E-commerce occupied Home Textile. China Textile, (3), 32-33.

Yang, F., Wang, A., \& Wu, J. (2017). Designing credit supervision mechanism in C2B2C e-commerce based on game theory. Systems Engineering-Theory \& Practice, 37(8), 2102-2110.

Zhu, B., Zhang, M., Huang, L., Wang, P., Su, B., \& Wei, Y. (2020). Exploring the Effect of Carbon Trading Mechanism on China's Green Development Efficiency: A Novel Integrated Approach. Energy Economics, 85, 104601. doi:10.1016/j.eneco.2019.104601 
Yi Sun was born in Jinan, Shandong, P.R. China, in 1982. He is an Associate Professor in the School of Economics and Management at University of Chinese Academy of Sciences. Yi Sun received his Ph.D. at the University of Chinese Academy of Sciences. His main research interests include Behavioral Finance, Financial Risk Management and Digital Economy and Digital Transformation.

Yunrong Li was born in 1983. Obtained PhD in Economics in 2014. Assistant professor at Dali University. Research interests are Applied Microeconomics, Labor Economics, etc. 